\title{
EL AUTOR ESPAÑOL EN EL FIN DE SIGLO
}

\author{
José Luis Alonso de Santos
}

Dramaturgo

Ante el fin del siglo, y la llegada del nuevo milenio, surgen en el autor dramático actual una serie de interrogantes sobre la orientación y el sentido de su trabajo, las líneas estilísticas y los contenidos básicos más apropiados en que desarrollar el mismo. El escritor trata de dar respuesta a las necesidades que gravitan sobre sus procesos imaginativos y creadores. En la busca de esa posible respuesta, bucea en sus experiencias personales, vivencias y situaciones y las confronta con el nuevo entorno que le rodea. Las preguntas básicas que se hacen en este fin de siglo son: ¿Qué teatro escribir hoy? ¿Cómo hacerlo? ¿Para qué y para quién escribir?

Las respuestas a esas preguntas son, lógicamente, tantas como escritores hay, y las diferentes etapas vitales que atraviesa cada uno de ellos. Múltiples variables van a incidir, pues, a la hora de producirse esa reacción que es escribir una obra de teatro. Pero sin duda habrá unas líneas generales que definan nuestra vivencia de escritores de hoy frente a creadores de otras épocas. De ellas vamos a tratar de hablar en esta breve reflexión sobre este tiempo que termina, y el nuevo que comienza. 
Como seres vulnerables que somos respondemos con nuestra escritura a nuestro entorno y a nosotros mismos. En ese proceso de acción-reacción entre la vida y el arte, van a surgir (al igual que surgen dentro de una acción dramática sobre el escenario) conflictos encadenados en un proceso causal puesto en marcha por la búsqueda de soluciones del autor ( $y$, en sus obras, de sus personajes). Y en las situaciones dramáticas que aporta un autor se esconden las proyecciones que hace el espectador de hoy de su propia búsqueda de metas y de resolución de sus propios conflictos.

¿Cómo incidir, pues, aquí y ahora en nuestra contemporaneidad, en nuestros conflictos y metas vitales como protagonistas de esta época de transición entre siglos -y milenios- que nos ha tocado vivir? Como autor que soy, puedo al menos hablar de cómo trato de responder yo a esa pregunta: el escritor teatral intenta, de una u otra forma, como un espía, comunicar los secretos por él descubiertos en el comportamiento humano, sorprendiéndose y sorprendiendo a los demás con lo extraño de nuestra conducta y de nuestro ser, tratando de transformar sus descubrimientos en un acto artístico sobre el escenario. Todo ello dentro de la complejísima tarea que supone intentar unificar, en la breve aparición del personaje durante el tiempo de su vida escénica la dispersión de actos, gustos, criterios, placeres y conflictos del ser humano en toda su vida.

Los autores tratamos, pues, de conseguir que el acto individual de la creación, que emprendemos al principio como una aventura íntima y solitaria, tenga posteriormente una carga de necesidad y sentido en dos direcciones:

1) Necesidad en cuanto al propio desarrollo teatral: la trama, los personajes, la estructura y la organización estética diferenciadora de la obra en sí.

2) Necesidad de aportar al espectador algo más allá del hecho teatral en sí mismo. Algo personal, válido y globalizador que el hecho dramático ha de provocar en él.

De alguna manera es como si cada espectador que va al teatro y paga su butaca para ver una obra nuestra, dedicándonos dos horas de su vida, nos hubiera hecho el encargo mucho tiempo antes, cuando iniciamos el proceso de creación: «Escribe una obra para que yo vaya a 
verla dentro de un tiempo y me aporte lo que yo necesite en ese momento». Luego, transcurrido ese tiempo, irá a recibir lo que encargó - como una comida especialmente preparada para saciar un hambre interna, difícil de definir y fácil de comprender por compartida-. Por eso se sentirá defraudado si no encuentra lo que necesitaba. Cuando el teatro no responde a las necesidades reales del espectador, a ese encargo no formulado directamente, éste siente que no está ganando su tiempo, sino perdiéndolo.

Es importante intentar conectar con el espectador de nuestra época, adivinando ese encargo íntimo, hablándole con lenguaje de hoy, de problemas de hoy, tratando de aportar vitalidad, energía, unidad y estilo a nuestro trabajo, para poder tener así un diálogo sincero y real con el público, dentro de esa convención creíble que es el teatro, metiendo las manos en el barro de nuestro tiempo para crear con él personajes, situaciones y conflictos.

Frente a los medios de comunicación masivos, los grandes poderes de las multinacionales, los bloques de poder, la información mundial instantánea, etc. (en los que el hombre se siente como un mero y lejano espectador), surge hoy en nuestro teatro una nueva subjetividad, un refugiarse en lo interior y cuestionarse desde allí el ser humano preguntas íntimas sobre su conciencia de existir. El papel del autor en nuestros días es el de bucear en el terreno de lo personal, lo corporal y lo biológico, intentando llegar así a un nuevo lenguaje escénico acorde con nuestro tiempo y nuestras necesidades.

La cercanía del fin de siglo, y cierto desencanto ante las expectativas generadas en los diferentes cambios habidos en nuestro país, así como un cierto desengaño sobre las soluciones colectivas y utópicas que formulaban otros horizontes años atrás, crean una cierta melancolía y un cierto pesimismo poético: hacer de la fragilidad y limitación humana belleza, se convierte así en otro de los objetivos del escritor actual.

Se proponen hoy como temas de nuestro tiempo aquéllos que afectan más a la realización personal del hombre: el amor, la desesperanza, el dinero, el sexo, la violencia, la agresión, el derecho al «no» y a la razón individual, el descubrimiento de que las cosas no son como parecen, la conciencia de extranjeros en un mundo que no es «nuestro», la búsqueda de unos pilares éticos diferentes, la elaboración de una nueva esperanza, el sentido de la utilidad y la busca del hueco humano y social, el diálogo con nosotros mismos, el derecho al viaje 
iniciático de cada ser... y el debate, social, por un lado, e íntimo, por otro, entre nuestra realidad y nuestro deseo. Temas, como se ve, que van desde lo más elemental y primario hasta lo más abstracto, y que, en el fondo, forman parte del teatro de todos los tiempos, pero enfocados ahora con un lenguaje y una actitud más directa y cercana a nuestra sensibilidad.

El teatro, terreno ideal para la crisis y el cuestionamiento, ya que se alimenta de ellos, recoge toda esa problemática de esta época, esos conflictos, construyendo con ellos un material dramático básico. Sube así el hombre corriente de hoy al escenario, lugar ocupado durante mucho tiempo por las aventuras y desventuras del príncipe, del jefe, del señor, del amo. El personaje de hoy, por tanto, tiene hoy algo de «común» con el espectador. El autor tratará de hacerle, a su vez, «peculiar» para que, sin dejar de ser reconocible, nos sea interesante. $Y$ le hará vivir un papel, es decir, un recorrido hacia sus metas, dándonos al final, con el desenlace, un punto de vista sobre el aquí y el ahora, lo más significativo y clarificador posible.

El hombre y sus conflictos por tener una vida más plena han sido, pues, el primer material dramático de este periodo histórico. Líneas, tendencias, estilos y diferentes formas nos han servido para ayudar a lograr, mediante lenguajes teatrales acordes con el sentido de la obra, que la historia de ese ser humano sobre el escenario, y sobre el mundo, siga adelante.

\section{UN BALANCE GENERAL}

Cuando nos quedan apenas unos meses para terminar este agitado siglo XX, si tratamos de hacer una valoración del panorama teatral de nuestro país podemos caer fácilmente en una de las dos posturas extremas existentes en este momento sobre la salud del arte escénico: una más pesimista y otra más optimista, ambas generalmente de tipo subjetivo y que suelen depender de la situación personal de cada autor, director o creador teatral consultado. No hay datos reales de la asistencia de espectadores (los únicos son los de la Sociedad General de Autores y Editores sobre el control de los derechos de autor, y sólo recogen la asistencia a los teatros de las grandes ciudades con taquilla abierta). En cuanto a la calidad de lo representado en los últimos años 
hay opiniones para todos los gustos: desde los que afirman que la crisis del teatro actual es total, tanto en cantidad como en calidad, a los que opinan que vivimos dentro de un gran momento creativo.

Si tuviera que definirme al respecto, me quedaría en un término medio. Soy un asiduo espectador de teatro (de todas las formas y estilos) y veo una media de un par de obras a la semana, lo que da un resultado de unas cien obras al año. Entre ellas hay siempre buenas y malas representaciones, espectáculos innovadores y otros apoyados en la tradición y la historia teatral, autores clásicos y de esta época, etc.

Puesto a concretar este balance en el terreno específico del autor español actual, creo que se han dado en estas últimas temporadas una docena de obras estimables al año, entre la media de unas doscientas que se han estrenado cada temporada en nuestro teatro público y privado, y en las salas alternativas donde tienen acogida muchos de nuestros autores más jóvenes.

Por otro lado, en los nuevos planes de estudio de las Escuelas e Institutos Superiores de Arte Dramático, se ha creado la especialidad de Dramaturgia, de donde cada año sale, desde 1996, una nueva generación de escritores teatrales, lo que dará, sin duda, en el futuro, unos resultados positivos en la creación de nuevos textos.

Es muy delicado para un autor teatral como yo citar a sus compañeros que considera más importantes y representativos en este momento, ya que inevitablemente tendría que postergar a otros. Los libros de historia del teatro de esta época, por un lado, y la cartelera teatral por otro, son un termómetro estimable para situar la validez de la obra de unos y otros, teniendo en cuenta, claro está, que sobre gustos es difícil opinar, y que no ha pasado el tiempo suficiente para que se instalen nuestras obras en la historicidad de este periodo, quedando unas como significativas y desapareciendo otras con el paso de los tiempos, como ha pasado en cualquier otro momento de la historia. No obstante creo necesario dar alguna referencia, si no de calidad al menos de cantidad, de los autores más representados.

Según la lista de autores publicados en la colección de la Sociedad General de Autores y Editores en los últimos seis años (que selecciona las obras de autor español estrenadas que han tenido una mayor repercusión de crítica y público), en una lista de cerca de cien títulos encontraríamos que los autores que hemos estrenado mayor número de obras en este periodo somos: Francisco Nieva, Juan José Alonso Millán, Santiago Moncada, Jaime Salón, Albert Boadella, José 
Sanchis Sinisterra y el autor que estas líneas escribe. Habría que añadir otros autores que no publican en esta colección pero que estrenan con normalidad, como Antonio Buero Vallejo o Antonio Gala. La enumeración de autores con mayor número de estrenos y representaciones estos últimos años del siglo, se completaría con nombres como Sergi Belbel, Rafael Mendizábal, Ernesto Caballero, Paloma Pedrero, Benet y Jornet...

\section{DECÁLOGO ORIENTADOR}

Trataré a continuación de dar unas breves referencias orientativas de lo que para mí ha caracterizado los últimos años de nuestro teatro. Notas siempre inevitablemente generalizadoras y personales, que tienen muchos matices y sus excepciones lógicas:

1. Deja de influir con la fuerza que lo había hecho en años anteriores el teatro llegado del resto del mundo en los festivales internacionales de teatro, y cobra más importancia la producción nacional. Es significativo también a este respecto la desaparición de algunos de estos festivales, como el Festival Internacional de Teatro que se celebraba en Madrid, etc.

2. Mientras se mantienen los altos presupuestos de los teatros oficiales y estatales de producción pública, los apoyos económicos de las distintas Administraciones al resto del teatro baja de forma notable. El teatro de producción privada sufre una crisis económica considerable de la que sólo se salvan los éxitos reconocidos de cada temporada.

3. Estrenan sus obras muchos autores jóvenes, aunque normalmente en circuitos alternativos de bajo presupuesto y con un público minoritario. Esta generación de jóvenes autores encabeza en la actualidad en las salas alternativas un importante movimiento de renovación teatral.

4. Ha crecido la asistencia al teatro en muchos puntos del Estado español, sobre todo a partir de la creación de la red de teatros públicos, mientras que ha disminuido el número de espectadores en Madrid, aunque últimamente se ha compensado con la asistencia a espectáculos musicales de gran éxito. Es importante reseñar que el espectador 
teatral sigue siendo muy minoritario en nuestro país, en comparación con entretenimientos o actos de comunicación masiva como fútbol, televisión, etc.

5. Sigue habiendo, y cada vez de forma más evidente, un choque entre el precio que deben tener las localidades para cubrir los altos costes de un espectáculo actual y lo que el espectador está dispuesto a pagar para ver teatro, en competencia con la televisión, que es gratuita. La gran pregunta en política cultural de la época es hasta que punto los organismos de cultura de las diferentes Administraciones deben asumir parte de esos costes. Sigue en pie, pues, el debate sobre la necesidad o no de las subvenciones, y, de ser necesarias, cómo y con qué criterios se han de conceder. Dados los altos impuestos que ha de soportar el teatro en la actualidad, sus altos costes y la tarea de dinamización cultural y defensa del patrimonio artístico que realiza, es indudable que debe tener apoyo económico, y con la misma valoración e importancia que lo hay para el cine, la ópera, la música, etc.

6. La aceptación de cierto eclepticismo en cuanto a las formas teatrales es otra de las características de esta época. Vanguardia y tradición, comedia y tragedia, teatro de entretenimiento o con gran ambición artística, teatro formal y teatro de contenido, teatro clásico y moderno, etc. conviven en estos años en relativa armonía entre nosotros, rebajando la tensión de las fuertes batallas estéticas entre creadores de otros tiempos. Ver, por ejemplo, la programación de estos años de la Muestra de Teatro de Autores Españoles de Alicante, donde están incluidas diversas formas y tendencias de nuestro teatro, nos da una idea aproximada de esta tregua entre las gentes de teatro de diferentes estilos y tendencias, frente a los poderosos enemigos exteriores que nos acechan.

7. La Asociación de Autores de Teatro cuenta actualmente con más de ciento cincuenta socios. A los concursos de obras teatrales de nuestro país se presentan una media de cien obras, y cada año se estrenan o reponen unas doscientas obras de autores españoles vivos. Estos espectáculos tienen diferente repercusión y valoración, como es natural, pero cada año suele haber entre ellos dos o tres, al menos, que consiguen gran éxito de crítica y público.

8. Los grupos catalanes se han situado en este periodo en la punta de lanza del movimiento teatral por la importancia de sus espectáculos, cantidad de espectadores, presupuestos económicos en que se han movido, etc. (La Cubana, Els Joglars, La Fura dels Baus, Comedians, Dagoll Dagoll, Teatre Lliure, Tricicle, etc.). 
9. En los últimos años se ha consolidado la Compañía Nacional de Teatro Clásico. El conjunto de sus producciones ha sido uno de los elementos más significativos e importantes teatralmente de toda esta época.

10. Después de un tiempo en que el autor estaba postergado por corrientes y estéticas dominantes anti-textuales, surge de nuevo con gran fuerza la defensa de un teatro de texto. No se trata de la recuperación del teatro literario de otros tiempos, sino del reconocimiento de una necesaria síntesis entre los lenguajes escénicos y la escritura dramática.

\section{UNA MIRADA HACIA EL FUTURO}

El futuro del teatro, y más aún el teatro de autor español actual, es incierto. La protección, apoyo y fomento de nuestras autoridades que ocupan cargos en los departamentos de cultura, será decisivo en los próximos años. El debate sobre si el teatro debe someterse exclusivamente a las leyes del mercado y a las de la oferta y la demanda, o si se debe ejercer sobre él una tutela y protección, está abierto en este momento en nuestro país.

Mi postura ya la he expresado anteriormente: el equilibrio entre lo público y lo privado, entre la protección y la dependencia, entre la búsqueda del éxito y la búsqueda de nuevas vías para la creación, entre nuestros autores de otra época y los nuevos creadores, entre el teatro concebido como una industria del ocio y el teatro como un servicio público cultural y educativo, con fines artísticos, sería el mejor camino para permitir que el nuevo siglo no fuera para nuestro arte escénico un tiempo agónico y oscuro, sino el comienzo de una nueva época, llena de vitalidad y energía creadora.

Asimismo es importante que los creadores asumamos la necesidad de abrimos a nuevas experiencias escénicas, a nuevas formas de comunicación con el espectador, y a organizar nuestro trabajo en formas de producción alternativas a la empresa teatral de tiempos pasados, que permitan la incorporación de los jóvenes creadores para alimentar así, con todo ello, esa fuerza llena de belleza, verdad y creación del hombre que vive entre nosotros desde hace dos mil quinientos años: el teatro. 
El cercano siglo XXI nos abre el interrogante de cómo será el teatro de la nueva época. Caminaremos hacia él con la seguridad de que será vivo y radiante, a pesar de la eterna crisis en que vivimos los hombres que lo creamos cada día, desde que nació hasta hoy, dada nuestra naturaleza. La pequeña metáfora de vida que es una obra dramática sobre el escenario, seguirá estando así dispuesta, como bola de cristal de mago, a descubrimos dimensiones escondidas de nuestra realidad personal e histórica, y a transformar la angustia de existir en reflexión sobre la vida, en acto lúdico y en belleza. Para que la lucha que empezaron nuestros fundadores hace tantos siglos (Esquilo, Sófocles, Eurípides, Aristófanes... ) por entablar un diálogo con los dioses, la naturaleza y los otros hombres, siga en pie, tratemos entre todos de que el teatro siga siendo la patria de la convivencia, la alegría de vivir y la esperanza de un futuro mejor, en que las palabras «verdad», «belleza», «dignidad» y «armonía del hombre con el mundo», recobren su sentido más profundo. 